This is an electronic reprint of the original article. This reprint may differ from the original in pagination and typographic detail.

Author(s): Laitinen, Mikko; Riihimäki, liro; Ekman, Jörgen; Sagari A.R. , Ananda; Karlsson, L.B.; Sangyuenyongpipat, Somjai; Gorelick, Sergey; Kettunen, Heikki; Penttilä, Heikki; Hellborg, R.; Sajavaara, Timo; Helgesson, J.; Whitlow, Harry

Title: $\quad$ Mobility determination of lead isotopes in glass for retrospective radon measurements rad

Year: $\quad 2008$

Version:

Please cite the original version:

Laitinen, M., Riihimäki, I., Ekman, J., Sagari A.R., A., Karlsson, L., Sangyuenyongpipat, S., Gorelick, S., Kettunen, H., Penttilä, H., Hellborg, R., Sajavaara, T., Helgesson, J., \& Whitlow, H. (2008). Mobility determination of lead isotopes in glass for retrospective radon measurements rad. Prot. Dos., (131), 212.

All material supplied via JYX is protected by copyright and other intellectual property rights, and duplication or sale of all or part of any of the repository collections is not permitted, except that material may be duplicated by you for your research use or educational purposes in electronic or print form. You must obtain permission for any other use. Electronic or print copies may not be offered, whether for sale or otherwise to anyone who is not an authorised user. 


\section{MOBILITY DETERMINATION OF LEAD ISOTOPES IN GLASS FOR RETROSPECTIVE RADON MEASUREMENTS}

Mikko Laitinen ${ }^{\mathrm{a},}$, liro Riihimäki ${ }^{\mathrm{a}}$, Jörgen Ekman ${ }^{\mathrm{b}}$, A. R. Ananda Sagari ${ }^{\mathrm{a}}$, Lennart B. Karlsson ${ }^{\mathrm{b}}$, Somjai Sangyuenyongpipat ${ }^{\mathrm{a}}$, Sergey Gorelick $^{\mathrm{a}}$, Heikki Kettunen ${ }^{\mathrm{a}}$, Heikki Penttilä $^{\mathrm{a}}$, Ragnar Hellborg ${ }^{\mathrm{c}}$, Timo Sajavaara ${ }^{a}$, Johan Helgesson ${ }^{b}$, Harry J. Whitlow ${ }^{a}$

${ }^{a}$ Department of Physics, University of Jyväskylä (JYLF), P.O. Box 35, FIN-40014 Jyväskylä, Finland. ' ${ }^{\circ}$ School of Technology and Society, Malmö University, SE-205 06 Malmö, Sweden. ${ }^{\mathrm{c}}$ Department of Physics, Lund university, P.O. Box 119, SE-22100 Lund, Sweden

Received on , 2007, revised on , 2007, accepted on , 2007

In retrospective radon measurements the 22 year half life of ${ }^{210} \mathrm{~Pb}$ is used as an advantage. The ${ }^{210} \mathrm{~Pb}$ is oftenconsidered to be relatively immobile in the glass after alpha recoil implanted by ${ }^{222} \mathrm{Rn}$ progenies. The diffusion of ${ }^{210} \mathrm{~Pb}$ could however lead to uncertain wrong retrospective radon exposure estimations if ${ }^{210} \mathrm{~Pb}$ is mobile and can escape from glass, or lost as a resulting of cleaning- induced surface modification. This diffusion was studied by radiotracer technigue where ${ }^{209} \mathrm{~Pb}$
was used as a tracer in a glass matrix for which the elemental composition is known. Using the IGISOL technique the ${ }^{209} \mathrm{~Pb}$ atoms were implanted into the glass with an energy of $39 \mathrm{keV}$. The diffusion profiles and the diffusion coefficients
were determined after annealing at $470-620^{\circ} \mathrm{C}$ and serial sectioning by ion sputtering. In addition the effect of surface cleaning on diffusion was tested. From the Arrhenius fit the activation enthalpy was determined to be $H=(3.2 \pm 0.2) \mathrm{eV}$ and the pre-exponential factor $D_{0}$ in the order of $20 \mathrm{~m}^{2} \mathrm{~s}^{-1}$. This result confirms the assumption that over time period of 50 years the ${ }^{209} \mathrm{~Pb}$ (and ${ }^{210} \mathrm{~Pb}$ ) is effectively immobile in the glass. The boundary condition obtained from the measurements had characteristic of a sink implying loss of ${ }^{209} \mathrm{~Pb}$ in the very surface at high temperatures.

\section{INTRODUCTION}

It is estimated that radon in dwellings accounts up to $2 \%$ of all deaths from cancer in Europe [1]. This number is higher in the areas where higher concentrations of the natural uranium exists in the bedrock. To make accurate conclusions of radon induced fatalities it is important to have reliable method for measuring radon concentrations for a sufficient long time period. Starting from the ${ }^{238} \mathrm{U}$ the radium decay series acts as a constant source of radioactive decay products. The half life of $t_{1 / 2}=$ $3.8 \mathrm{~d}$ of the radon(222) gas allows ${ }^{222} \mathrm{Rn}$ to diffuse out from the ground and to the dwellings. It is however not the radon itself that causes most of the exposure but the short lived alfa-emitting solid progenies of the inhaled radon [I]

Epidemiological surveys where radon retrospective measurements are used are based on surface traps such as glass $[2,3,4,5,6]$ for determining the alpha recoil implanted radon progenies. Also substrates like CR-39 or other polymers is widely used for retrospective radon measurements, progeny detection and in epidemiological studies; see $[7,8,9,10]$ for example.

When ${ }^{222} \mathrm{Rn}$ decays the radium decay series quickly evolves but builds up after about an hour to in ${ }^{210} \mathrm{~Pb}$ The long half life of $t_{1 / 2}=22 \mathrm{a}$ of the ${ }^{210} \mathrm{~Pb}$ is what enables the retrospective radon measurements when the

*Corresponding author: Mikko Laitinen, tel.: +358 14260 2419; fax: +358 14260 2465. E-mail address: mikko.laitinen @ jyu.fi implanted ${ }^{210} \mathrm{~Pb}$ (or it's progenies) concentrations into the glass can be determined reliably.

Most of the retrospective radon measurements based on the surface trap method does not however take into account the possibility of the diffusion of the ${ }^{210} \mathrm{~Pb}$. Implantation depth of ${ }^{210} \mathrm{~Pb}$ from alpha decays of ${ }^{218} \mathrm{Po}$ and ${ }^{214} \mathrm{Po}$ is very shallow and $\leq 100 \mathrm{~nm}$ at the maximum [11, 12]. This can lead to erroneous results if the ${ }^{210} \mathrm{~Pb}$ is mobile and diffuses out from the glass. This is because most of the implanted ${ }^{210} \mathrm{~Pb}$ is concentrated very close to the surface $[11,12]$.

In retrospective radon measurements alpha activities of $2 \mathrm{~Bq} \mathrm{~m}{ }^{-2}$ of ${ }^{210}$ Po can be measured [3]. Calculated from decay constants this polonium activity corresponds to about $4 \times 10^{7}{ }^{210} \mathrm{~Pb}$ at. $\mathrm{cm}^{-2}$. The diffusion processes where only very small concentration ( $10^{7}-10^{10} \mathrm{at} . \mathrm{cm}^{-2}$ ) of implanted atoms exists can only be studied by the radiotracer technique [13]. To measure the diffusion of ${ }^{210} \mathrm{~Pb}$ we used ${ }^{209} \mathrm{~Pb}$ as a radiotracer to mimic ${ }^{210} \mathrm{~Pb}$ as from the diffusion perspective they only differ by their mass which can be safely disregarded. This study further investigates the surface escape of the $\mathrm{Pb}$ and expands the reliability of the initial study [14] of the low concentration diffusion of $\mathrm{Pb}$ in glass.

\section{METHOD}

To measure diffusion by radiotracers at low concentrations the implanted isotopes need to have a half life between $\sim 30 \mathrm{~min}$ and few tens of hours so that enough statistics from $\beta$-decays can be collected in short period 


\section{LAITINEN ETAL}

of time. At Jyväskylä a primary energetic beam from the $\mathrm{K}-130$ cyclotron is guided to a solid target at the ion guide isotope separator on-line (IGISOL) $[15,16,17]$ where the radioactive products are isotope separated and accelerated to a maximum energy of $40 \mathrm{keV}$ for implantation. After the implantation the sample is thermally annealed in vacuum to induce diffusion. Subsequently, the concentration profile of implanted ${ }^{209} \mathrm{~Pb}$ was serially sectioned onto thin mylar foils by a sputtering method [18].

After sputtering the activity on each section was measured and the total crater depth of the sputtered sample determined. For different temperatures the diffusion profiles are determined from the crater depth, number of foils and from the measured activity on each foil.

The mathematical form of the diffusion profiles can be deduced from Fick's law [19, 20, 21] (see Eq. 1). Prior to fitting, the measured profiles were corrected for radioactive decay during the measurement. Diffusion equation

$$
\begin{array}{r}
C_{P b}(x, t)=N \int_{0}^{\infty}\left[\exp \left(\begin{array}{c}
\left(x-x^{\prime}\right)^{2} \\
4 \lambda^{2}
\end{array}\right)\right. \\
\left.+R \cdot \exp \left(-\frac{\left(x+x^{\prime}\right)^{2}}{4 \lambda^{2}}\right)\right] C_{P b}\left(x^{\prime}, t=0\right) d x^{\prime} .
\end{array}
$$

relates the evolution of the concentration profile $C_{P b}(x, t)$ with depth $x$ and time $t$ to the initial, asimplanted profile $C_{P b}(x, t=0) . \lambda$ is the diffusion length.

In eq. (1) the shallow implantation depth from the surface has been taken account by $R(-1 \leq R \leq+1)$ which describes the surface boundary condition. $R=-1$ for a perfect sink while $R=+1$ corresponds to a perfectly reflecting boundary [21]. The as-implanted profile $\mathrm{C}_{P b}(\mathrm{x}, \mathrm{t}=0)$ was taken to have a Gaussian form where $x_{0}$ is the centroid of the as-implanted profile. Fig. 3 shows this to be a good approximation to our experimental data. When Eq. (1) is integrated it can be represented in the form:

$$
\begin{array}{r}
C_{P b}(x, t)=N\left[\operatorname{erfc}\left(--\frac{\frac{x_{1}}{2 \nu^{2}}+\frac{x}{4 \lambda^{2}}}{\sqrt{\frac{1}{2 \nu^{2}}}+\frac{1}{4 \lambda^{2}}}\right)\right. \\
\exp \left(-\frac{\left(x-x_{0}\right)^{2}}{2 \nu^{2}+4 \lambda^{2}}\right)+R \cdot \operatorname{erfc}\left(-\frac{\frac{x_{0}}{2 \nu^{2}}-\frac{x}{4 \lambda^{2}}}{\sqrt{\frac{1}{2 \nu^{2}}}+\frac{1}{4 \lambda^{2}}}\right) \\
\left.\exp \left(-\frac{\left(x+x_{0}\right)^{2}}{2 \nu^{2}+4 \lambda^{2}}\right)\right]+B,
\end{array}
$$

where $\nu$ and $x_{0}$ are taken from the as-implanted Gaussian and $N, \lambda, R$ and $B$ are free parameters.

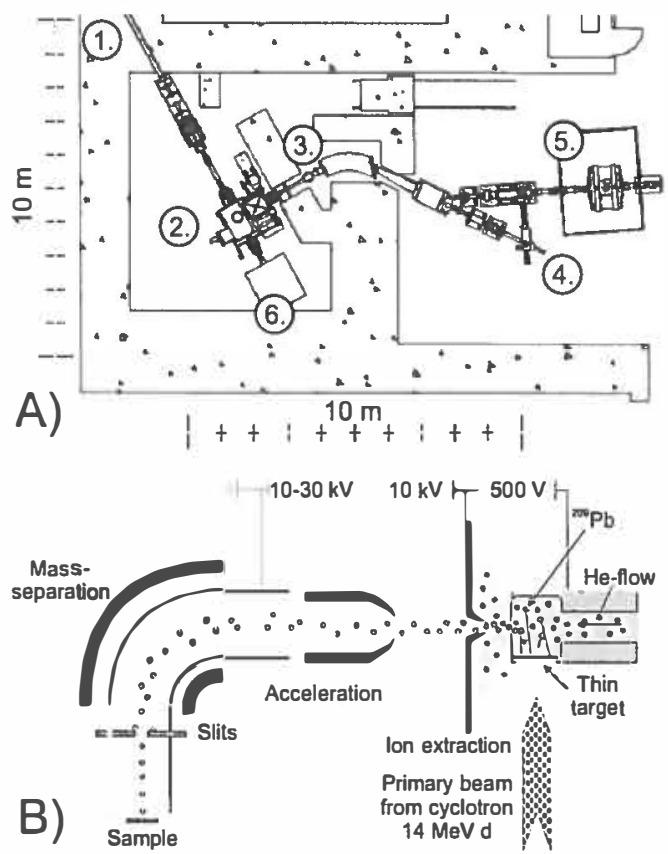

Figure 1. A) IGISOL-setup: 1. Primary beam from cyclotron, 2. Target chamber and ion extraction, 3. Mass separation, 4 Experiment setup, 5. Magnet with 2 Penning traps for nuclear measurements 6 . Beam dump and concrete shielding. B) Schematic of the experimental setup at point 4 in Fig. 1A).

The diffusion coefficients $D$, obtained from diffusion lengths $\lambda$ are then plotted against inverse temperature $\mathrm{T}^{-1}$ where the forming line is called Arrhenius fit.

By radiotracer method virtually any diffusion in any solid material can be measured when appropriate radiotracer exists and the annealing oven can reach the right temperature range.

\section{EXPERIMENT}

The elemental composition of the soda-lime glass used in the experiment was measured using time of flightelastic recoil detection (ToF-ERD) [22] analysis to be $\mathrm{Ca} 3 \%, \mathrm{Si} 26 \%, \mathrm{Mg} 3 \%, \mathrm{Na} 8 \%$, and $\mathrm{O} 60 \%$ respectively. The glass samples used were taken from the same batch (Menzel-Gläser $76 \times 26 \times 1 \mathrm{~mm}^{3}$ sized microscope slides, article number 011101 ) as our preliminary study [14].

To test influence on cleaning on diffusion and loss of $\mathrm{Pb}$ from the glass surface two sets of samples were cleaned in different ways. One set of samples were treated in $99.5 \%$ acetic acid for $>24 \mathrm{~h}$ prior to diffusion while another set was treated with a commercial window cleaner (Ajax $\mathrm{Tm})$ and rubbed with cotton wool on 
sticks for 20 minutes between implantation and thermal treatment.

The ${ }^{208} \mathrm{~Pb}(\mathrm{~d}, \mathrm{p})^{209} \mathrm{~Pb}$ reaction was used to produce $\beta^{-}$active ${ }^{209} \mathrm{~Pb}[23]$ with $\mathrm{t}_{1 / 2}=3.253 \mathrm{~h}$. The $14 \mathrm{MeV}$ deuterium beam was produced by the Jyväskylä cyclotron. Thin enriched ${ }^{208} \mathrm{~Pb}$ was used as a primary target material in IGISOL (Fig. 1). The ${ }^{209} \mathrm{~Pb}^{+}$ions were implanted in the glass samples with an energy of $39 \mathrm{keV}$. According to SRIM-2006 [24] the lateral implantation depth was $23.0 \mathrm{~nm}$ with stragling (square root of variance) of $4.3 \mathrm{~nm}$ when elemental composition was as measured with ToF-ERDA and density of $2.5 \mathrm{~g} \mathrm{~cm}^{-3}$ was used in the simulation.

After the implantation the activity in the sample was checked using a scintillation monitor to be sufficiently large to give a measurable activity over the whole measurement cycle $(\sim 4 \mathrm{~h})$.

The samples were heat-treated in a quartz vacuum tube at $1-5 \times 10^{-5} \mathrm{~Pa}$ mounted in a tube furnace (Gero Gmbh, type F) between $470-670{ }^{\circ} \mathrm{C}$. The annealing time was $1 \mathrm{~h}$ except for the lowest temperature where this was extended to $4 \mathrm{~h}$ to improve measurement accuracy.

Timing was started when sample was slided in the oven and stopped when taking out. Temperature saturation was slowest for the lowest temperatures but the gradients at the beginning and in the end of the annealing were expected to cancel each other out to some degree. Next the samples were taken to the serial sectioning [18]. The ion source for the sputtering system was ECR plasma source "OSPrey" from Oxford Scientific. Gas feedstock for the ion gun was air and the acceleration voltage of $1 \mathrm{kV}$ was used for the ion beam (Fig. 2). When the serial sectioning by sputtering to the mylar foil was completed the foil was taken out for activity measurement.

Activity of each foil section was measured with two large silicon detectors. Both detectors facing each other had an active area of $50 \times 50 \mathrm{~mm}^{2}$ and a thickness of $500 \mu \mathrm{m}$. Distance between the detectors was about 4$5 \mathrm{~mm}$. Each detector was segmented to four quadrants. Since the sputtered fluence in the foil had diameter of $\approx 30 \mathrm{~mm}$, detectors formed effectively $4 \pi$ detection angle. $\beta$-decay counts from ${ }^{209} \mathrm{~Pb}$ were collected for $200 \mathrm{~s}$ for each foil section. Maximum count rate was less than 25 counts/second. Counting electronics had veto pulses to discriminate signals too close each other $(\sim 1 \mu \mathrm{s})$. By this veto double/multiple counts caused by electron scattering from quadrant to quadrant were rejected.

The depth of the crater formed during the sputtering was measured from 4-10 positions around the implantation spot with P-15 stylus profiler from KLA-Tencor. The vertical resolution of the profiler is better than $2 \mathrm{~nm}$.

\section{ANALYSIS AND DISCUSSION}

The implantation depth $x_{0}$ measured from the Gaussian fit is $22.6 \pm 0.2 \mathrm{~nm}$ which is close to SRIM simulation

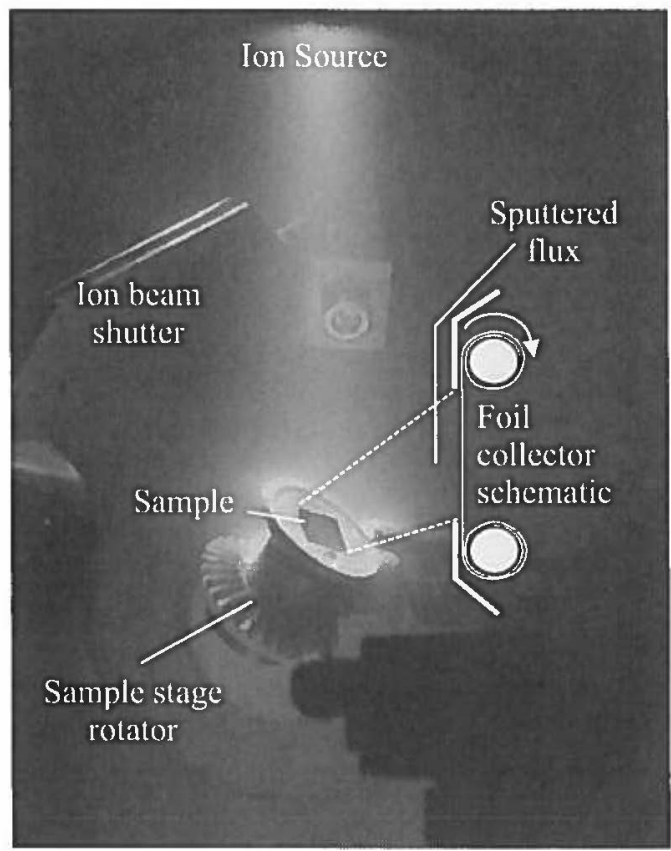

Figure 2. Photographic montage of the sample during serial sectioning. Incident $1 \mathrm{keV}$ ion beam erodes the sample and sputtered flux is collected on a mylar foil.

result. Figure 4 presents an Arrhenius plot of the diffusion coefficient $D=\lambda^{2} / t . \lambda$ is obtained from the Eq. (2) and $t$ is the annealing time.

The temperature dependence of $D$ follows the Arrhenius equation:

$$
D=D_{0} \exp \left(-\frac{H}{k T}\right)
$$

here $D_{0}$ is the so-called pre-exponential factor, $H$ is the activation enthalpy, $k$ is Boltzmann's constant and $T$ is temperature in Kelvin.

The fitted activation enthalpy was $3.2 \pm 0.2 \mathrm{eV}$ and $D_{0}$ in the order of $20 \mathrm{~m}^{2} \mathrm{~s}^{-1}$. The largest uncertainty factor in the measurements was the background in the foil activity measurement. Background deviation of a few percent in the measurements cause noticeable changes to the diffusion length and this is the main cause of the scatter from a straight line in Fig. 4. Error bars for the $T^{-1}$ and $D$ in Fig. 4 correspond to the delay in temperature ${ }^{1}$ stabilization in the annealing and

1 Temperature is the mean of the measured values 40 minutes before the end of annealing and the error-bars represent standard deviation of these values. 


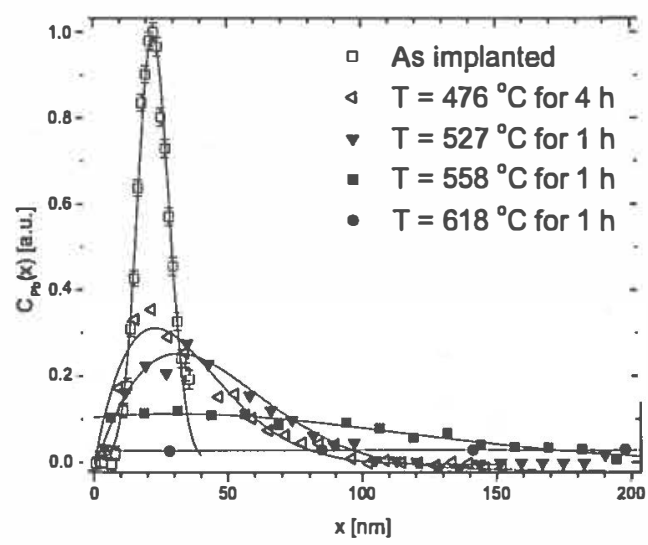

Figure 3. Measured as-implanted and annealed profiles. For clarity error bars are shown only in the as implanted profile as they are similar in size for the others. See text for further details.

to the diffusion data correlation to the fits ${ }^{2}$ (Fig. 3), respectively.

The diffusion length at the room temperature for ${ }^{209} \mathrm{~Pb}$ extrapolated over a time period of 50 years is in the order of $10^{-22}-10^{-23} \mathrm{~m}$. This result confirms that ${ }^{210} \mathrm{~Pb}$ is immobile in glass. This is a critical assumption in retrospective radon measurement by Samuelssson's method [3].

In contrast to our preliminary study the surface was found to be characteristic of a near-perfect $\operatorname{sink}(R \approx$ $-1)$. This is confirmed by inspection of Fig. 3 where $\mathrm{Pb}$ is seen to be depleted in the diffused profiles in the 30 $\mathrm{nm}$ closest to the surface. This is not inconsistent with the data in our previous study $[14,21]$. This means that if the ${ }^{209} \mathrm{~Pb}$ is diffused to the surface, it will escape from the sample under the conditions studied. Even if this holds true at the room temperature it affects only the very surface layer because, as shown above, in the glass ${ }^{209} \mathrm{~Pb}\left(\right.$ and ${ }^{210} \mathrm{~Pb}$ ) is immobile.

\section{CONCLUSIONS}

Diffusion coefficients of ${ }^{209} \mathrm{~Pb}$ in glass were measured over the temperature range of $470-620^{\circ} \mathrm{C}$. The activation enthalpy was determined to be $3.2 \pm 0.2 \mathrm{eV}$ and the pre-exponential factor $D_{0}$ in the order of 20 $\mathrm{m}^{2} \mathrm{~s}^{-1}$. Extrapolation of these diffusion parameters to room temperature shows that $\mathrm{Pb}$ is completely immobile in the glass over a time scale of 50 years. We also did not

2 Diffusion length error is calculated from the error obtained for the diffusion constants Eq.(2).

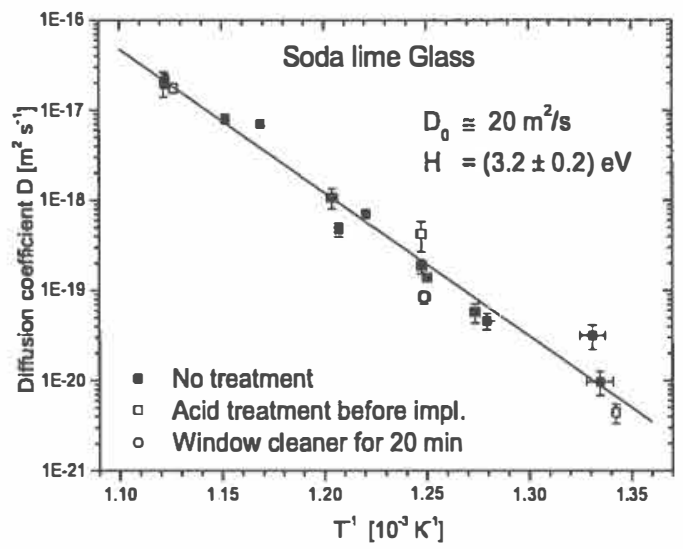

Figure 4. Arrhenius fit to the diffusion coefficients. All data points are used in the fit.

find differences in diffusion coefficients between the untreated samples, and the samples subjected to cleaning treatment by soaking in acid or a combination of commercial window cleaner and abrasion. For retrospective radon measurements where long decay time of ${ }^{210} \mathrm{~Pb}$ is used it can be confirmed that implanted ${ }^{210} \mathrm{~Pb}$ concentration does not alter due to diffusion mechanism. Over the temperature range of the measurements the surface behaved as an near-perfect sink, indicative of evaporation of the implanted $\mathrm{Pb}$ that diffuses to the very surface.

\section{ACKNOWLEDGEMENT}

This work was supported by the Academy of Finland under the Finnish Center of Excellence Programme 2006-2011 (Project 213503).

\section{REFERENCES}

I. S. Darby, D. Hill, A. Auvinen, J.M. Barros-Dios, H. Baysson, F. Bochicchio, H. Deo, R. Falk, F. Forastiere, M. Hakama, I. Heid, L. Kreienbrock, M. Kreuzer, F. Lagarde, I. Mäkeläinen, C. Muirhead, W. Oberaigner, G. Pershagen, A. Ruano-Ravina, E. Ruosteenoja, A. Schaffrath Rosario, M. Tirmarche, L. Tomásek, E. Whitley, H-E. Wichmann, R. Doll, Radon in homes and risk of lung cancer: collaborative analysis of individual data from 13 European case-control studies, British Medical Journal, 330, 223 (2005). 
2. R.S. Livily, E.P. Nhy, Sunfare madionativity from the deposition of Rm-222 daughter productss, Healdh Plinysics, 52, 411-415 (1987)).

3. C. Samulescom, Retrospective detenmimation of radom in howses, Narure, 334, 338-340 (1988).

4. C. Samulelson, Radom metrospactive measurements, Intermational Congress Series, 1276, 66-711 (2005)).

5. R. Falka, K. Almrénb, I. Östergrem, Experience from retrospective radom exposure estimations for individuals in a radon epidemiological study using sollid-state nuclear track detectors, The Science of The Tosal Environment, 272, $61-66$ (2001).

6. F. Lagarde, R. Fallk, K. Almrén, F. Nyberg, H. Svensson, G. Pershagen, Glass-based radonexposure assessment and lung cancer risk, Journal of Exposure Analysis and Enviromental Epidemiol. ogy, 12, 344-354 (2002).

7. J.A. Mahaffey, M.A. Parkhurst, A.C. James, F.T. Cross, M.C.R. Alavanja, J.D. Boice, S. Ezrine, P. Henderson, R.C. Brownson, Estimating past exposure to indoor radon from household glass, Health physics, 64, $381-391$ (1993),

8. M.C.R, Alavanja, J.H. Lubin, J.A. Mahaffey, R. Brownson, Residential radon exposure and risk of lung cancer in Missouri, American Journal of Public Health, 89, 1042-1048 (1999).

9. J.A. Mahaffey, M.C.R. Alavanja, M.A. Parkurst, E. Berger, R.C. Brownson, Estimation of past exposure history for analysis of a residential epidemiology study, Radiation Protection Dosimetry, 83(3), 239-247 (1999).

10. D.J. Steck, R.W. Field, The use of track registration decetors to reconstruct contemporary and historical airborne radon $(222 \mathrm{Rn})$ and radon progeny concentrations for radon-lung cancer study. Radiation measurement, 31, $401-406$ (1999).

11. B. Roos, C. Samuelson, Experimental methods of determining the activity depth distribution of implanted 210Pb in glass, Journal of Envinonmental Radionativity, 334, 135-151 (2002).

12. B. Roos, Studies on the Alpha-Recoil Implantation of ${ }^{214} \mathrm{~Pb}$ and ${ }^{210} \mathrm{~Pb}$ in Glass Surfaces, $P h D$ Thesis. Universing of Lund (2002).

13. P. Laitinen, I. Rïhimäài, J. Huikari, J. Räisänen, Versatile use of ion beams for diffusion studies by the modified radiouracer technique, Nuclear Instruments and Methods in Physics Reseandh $B$, 219-220, 530-533 (2004).

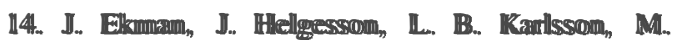

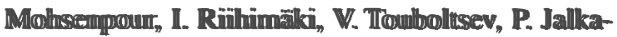
meem, A. Vinttamem, H. Keestmumen, J., Hurilkani, A. Niem-

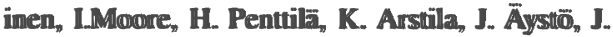
Räilissimem, H. J. Whitillow, Rethembion of Pb isotopes in gillasss ssunffaces ffor metrosipective assessment of maxdion expossure, Nhucllear Imsstruments and Methods in Physics Research Section B: Beamt Interactions with Materials and Atomss, 249, 544-547 (2006).

15. J. Āije, J. Äysstō, H. Hywö̈men, P. Taskinen, V. Koponen, J. Honksanen, K. Valli, A. Hautojärvi, $K$. Vierinem The ion guide isotope separator onlime, IGISOL, Nucllear Instruments and Methods in Physics Research A, 247, 431-437 (1986).

16. P. Dendooven, The development and status of the IGISOL trechnique, Nuclear Instruments and Methods in Physics Research Section B: Beam Interactions with Materials and Atomis, 126, 182-189 (1996).

17. J. Äystö, Development and applications of the IGISOL technique, Nuclear Physics A, 693, 477. 494 (2001).

18. P. Laitinen, M. Nevala, A. Pirojenko, K. Ranttila, R. Seppälä, I. Riihimäki, J. Räisänen, A. Virtanen, Utilisation of a sputtering device for targetry and diffusion studies, Nuclear Instruments and Methods in Physics Research B, 226, 441-446 (2004).

19. B. I. Boltaks, Diffusion in semiconductors, Infosearch Limited, London, 93-128 (1963).

20. C. Zaring, P. Gas, B.G. Svensson, M. Östling, H.J. Whitlow, Boron diffusion in bulk cobalt disilicide Thin Solid Films, 193-194, 244 (1990).

21. M. Salamon, Diffusion in Molybdändisilizid und in intermetallischen Phasen des Systems EisenAluminium, $P h D$ Thesis, University of Munster, 59 (2003).

22. J. Jokinen, J. Keinonen, P. Tikkanem, A. Kuronen, T. Ahlgren, K. Nordlund, Comparison of TOF-ERDA and nuclear resonance reactiom techniques for range profile measurements of $\mathrm{keV}$ energy implants, Nuclear Instrumeents and Methods in Physics Research B, 199, 533-542 (1996).

23. W. J. Ramler, J. Wing, D. J. Henderson, J. R Huizenga, Exitation Functions of Bismuth and Lead, Physical Review, 114, 154-162 (1959).

24. SRIM-2006.02, SRIM-2003 simulations, www.srim.org. 